\title{
Flourishing systems: re-envisioning infrastructure as a platform for human flourishing
}

Jennifer Schooling $\mathrm{PhD}$

Director, Department of Engineering, Centre for Smart Infrastructure and Construction, University of Cambridge, Cambridge, UK (Orcid:0000-00024777-0438)

Mark Enzer MA, MSc, MBA

Chief Technical Officer, Mott MacDonald, London, UK

\section{Didem Gurdur Broo PhD}

Research Associate, Department of Engineering, Centre for Smart Infrastructure and Construction, University of Cambridge, Cambridge, UK; Department of Engineering, Laing O'Rourke Centre for Construction Engineering and Technology, University of Cambridge, Cambridge, UK; Centre for Digital Built Britain, University of Cambridge, Cambridge, UK

(Orcid:0000-0002-8853-4159) (corresponding author: dg580@cam.ac.uk)

This paper describes how infrastructure should be considered a system of systems and its main purpose should be human flourishing. With this mindset, the paper underlines the importance of envisioning and managing infrastructure accordingly. We have created an amazing, complex machine on which we wholly depend. Without it, our lives would be immeasurably worse. Society would not survive. That machine is infrastructure - our built environment. However, we do not appreciate the relationship between the machine and our well-being. Therefore, we do not set objectives in terms of outcomes for people and society. Furthermore, although we understand each part of the machine, we do not manage it as a whole. Therefore, we do not know how to address its systemic vulnerabilities or make it work better. If we envision, plan and manage infrastructure differently, we can make it what it should truly be: a platform for human flourishing. This paper advocates a vision for infrastructure that is, firstly, people focused - recognising the fundamental role of infrastructure in the social, economic and environmental outcomes that determine the quality of people's lives - and, secondly, systems based - recognising infrastructure as a complex, interconnected system of systems that must deliver continuous service to society. It articulates how the industry should re-envision itself to unlock greater value for people, from the systems.

\section{Introduction}

Infrastructure and society are becoming more connected at an ever-faster pace, so risks of failure can cascade faster and wider than ever before. Challenges such as reducing carbon dioxide emissions ('carbon emissions') to net zero and making society resilient to the physical effects of climate change are systemic and require systems-based solutions (Schooling et al., 2020).

Throughout this paper, two concepts will be discussed. These concepts are 'flourishing' and 'systems'. The next two paragraphs explain these two concepts.

- Flourishing. Going back to Aristotle and beyond, the concept of human flourishing has been at the heart of the most basic of philosophical questions: what does it mean to live well? 'Eudaemonia', sometimes translated to 'happiness' (Kashdan et al., 2008), but best understood as 'human flourishing', is the ultimate good that people aim for, both as individuals and as society. More than personal wealth, honour or pleasure, it requires external conditions that are beyond the control of individuals but are related to the choices we make (Smith, 1999).

- Systems. A system is a connected collection of interrelated and interdependent parts, a complex whole that may be more than the sum of its parts. A system is influenced by its environment, defined by its structure and purpose and expressed through its function. Infrastructure is the interconnected 'system of systems' that provides the physical foundation for our society (Hall et al., 2016; Schooling et al., 2020). It does more than just provide water, power or transport services; it helps make cities liveable, boosts the quality of life and supports productivity and prosperity, all in the context of its interface with the natural environment (Fiksel, 2003).

This paper advocates a vision for infrastructure that is, firstly, people focused - recognising the fundamental role of infrastructure in the social, economic and environmental outcomes that determine the quality of people's lives - and, secondly, systems based recognising infrastructure as a complex, interconnected system of systems that must deliver continuous service to society. It articulates how the industry should re-envision itself to unlock greater value for people, from the systems.

To this end, the next section briefly describes the background by explaining earlier research and important concepts. In Section 3, a systems-based vision of infrastructure is described. The future directions and next steps are explained in Section 4. Finally, Section 5 presents the conclusion of this paper.

\section{Background}

'Flourishing systems' (Schooling et al., 2020) is the third in a series of 'principles' papers that reimagine infrastructure and the wider built environment. The first paper in the series (Bowers et al., 2018) focuses on smart infrastructure, whereas the second paper (Bolton 
Smart Infrastructure and Construction

Volume 173 Issue 1
Flourishing systems: re-envisioning

infrastructure as a platform for human

flourishing

Schooling, Enzer and Broo

et al., 2018) outlines the principles for development of digital twins. Before focusing on how infrastructure, as a system of systems, could be a platform for human flourishing, it is vital to explain a few concepts, which will be mentioned throughout this paper. One of the most important concepts is smart infrastructure. The EU Agency for Cybersecurity defines smart infrastructure as follows: 'Smart Infrastructures comprise several operators from different domains of activity, such as energy, public transport, public safety. They deploy and operate "cyber-physical systems", that are data-controlled equipment which interact with the physical world. They collaborate and exchange data under several schemes, depending on their level of maturity' (Enisa, 2019: p. 1). Smart infrastructure is where physical meets digital and sets out its core value proposition - that better decisions, based on better analysis of better data, drive better outcomes for people (CSIC, 2019). An example of smart infrastructure is smart transportation systems, where different forms of transportation agencies, modes, models and the like are integrated.

Another important concept is the digital twin. A digital twin is a realistic digital representation of assets, processes or systems in the built environment; what makes it a twin is the data connection between digital and physical (Batty, 2018). An example of a digital twin can be digital representation of a transportation system, which has integration with the physical system through different types of sensors and actuators and reads data and runs simulations by considering these new data points, to inform the decision makers of the system and improve their decisions. To support the development of digital twins, the Centre for Digital Built Britain (Neely et al., 2019) created the Gemini principles. The Gemini principles define digital twins for the built environment as connected digital representations of assets, processes and systems - and describe national digital twins as ecosystems of connected digital twins. The Gemini principles suggest the values that should guide the

\section{Purpose \\ Must have \\ a clear purpose}

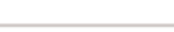

Trust

Must be trustworthy

Function Must function effectively
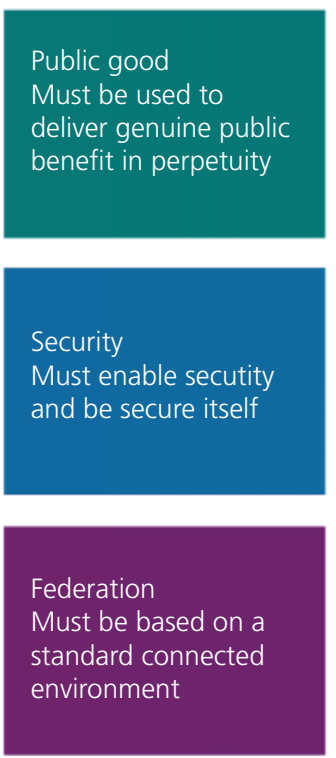

development and use of the UK's National Digital Twin (Bolton et al., 2018). They are organised under three overarching headings: purpose, trust and function (Figure 1).

A further related concept is the information-management framework. An information-management framework is a proposed framework for enabling effective information management, and in this paper, it is used specifically in the context of the built environment. Its intent is to help put the right information in the right hands at the right time to make the right decisions (Schooling et al., 2020).

Lastly, it is important to define and explain what is meant by interoperability in this paper. Interoperability is the ability of two or more systems to exchange information and to use the information that has been exchanged.

\section{Systems-based vision of infrastructure}

The systems-based vision for infrastructure is at the core of this proposition and aims to bring people, connections, sustainability and digitalisation perspectives together and create a systemic view for infrastructure. The next subsections explain these perspectives in detail.

\subsection{People}

This perspective builds on the idea that human flourishing is the fundamental purpose of infrastructure. There is an enduring interdependency between infrastructure and society - it is a socio technical system. Therefore, desirable outcomes for society should set the objectives for infrastructure.

The balance between social, environmental and economic outcomes (Figure 2) is an ethical and political matter. The interdependencies of these outcomes should be understood better so that we can influence
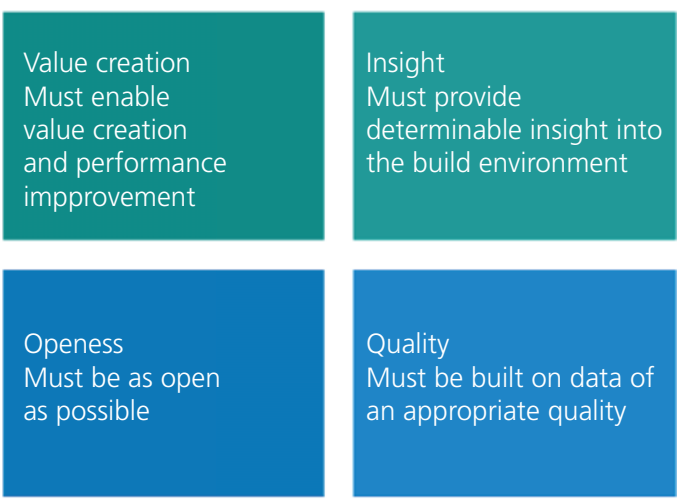

Curation

Must have clear

ownership, governance

and regulation
Evolution

Must be able to adapt

as technology and

society evolve 


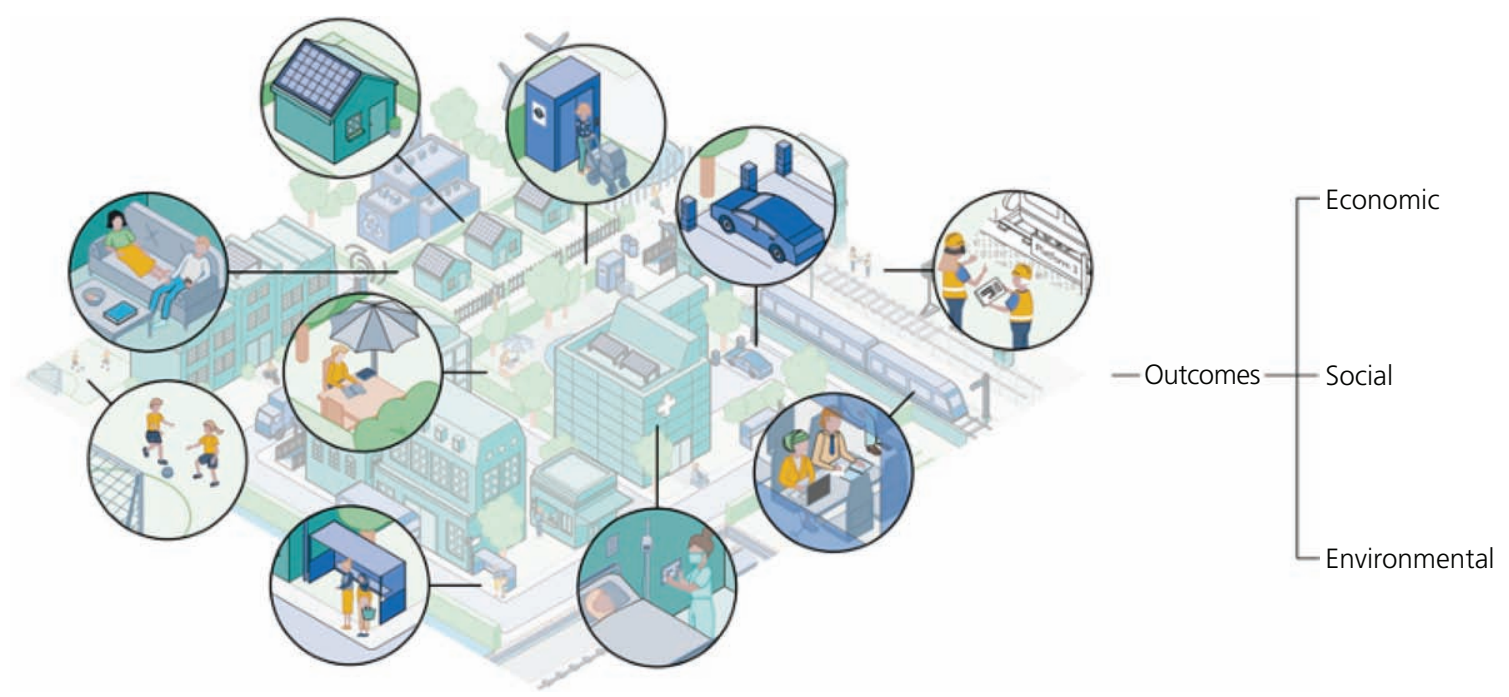

Figure 2. Importance of the balance between social, environmental and economic outcomes and their dependence on multiple infrastructures (Schooling et al., 2020)

them. While this paper does not aim to set that balance, it does encourage discussion between the infrastructure industry, government and society about what outcomes are desired from infrastructure. Moreover, critically, it seeks to recognise those outcomes as the objectives for the industry.

Value must be defined accordingly. The 'construction industry' has traditionally defined value in terms of outputs and initial cost. A people-focused 'infrastructure industry' would consider value in terms of outcomes and whole-life cost. The value should be considered beyond a financial measure and should be considered throughout the life of infrastructures.

Several projects in the UK work towards this amended value definition. For example, Project 13 (ICE, 2020), developed by the Infrastructure Client Group, champions this approach. Additionally, the UK's Construction Leadership Council and the Construction Innovation Hub have contributed further to align procurement processes with this definition of value $(\mathrm{CIH}, 2020)$.

Related to the people perspective, the servitisation concept and the servitisation of infrastructure - framing it as a service - offers an opportunity to put people first and enable us to start seeing infrastructure as a 'system of services' - for example, 'mobility as a service' in transport (Kamargianni et al., 2016).

With a people-focused view of infrastructure, the 'use' of the system (Figure 3) should be the start and end points of all other system processes (Schooling et al., 2020). The addition of each asset and its subsequent life cycle must be understood in relation to the broader system. This life cycle includes plan, design, build, commission and operate. In this way, all infrastructure projects can be seen as 'interventions' on the system, which allows us to see how different assets are interacting with the rest of the system. Such a view would help the industry integrate new assets, of all sizes, into the system more effectively.

\subsection{Connections}

Infrastructure has become a complex, highly interconnected system of systems (Hall et al., 2016) that people and society are dependent on. New characteristics of infrastructure should be reflected in the way we run the industry (Schooling et al., 2020). Only by taking a holistic view and identifying the interconnections between these systems can the complexity of this socio technical system be understood and mastered. This requires a focus on delivering desired outcomes from existing as well as proposed assets - the whole of our built environment.

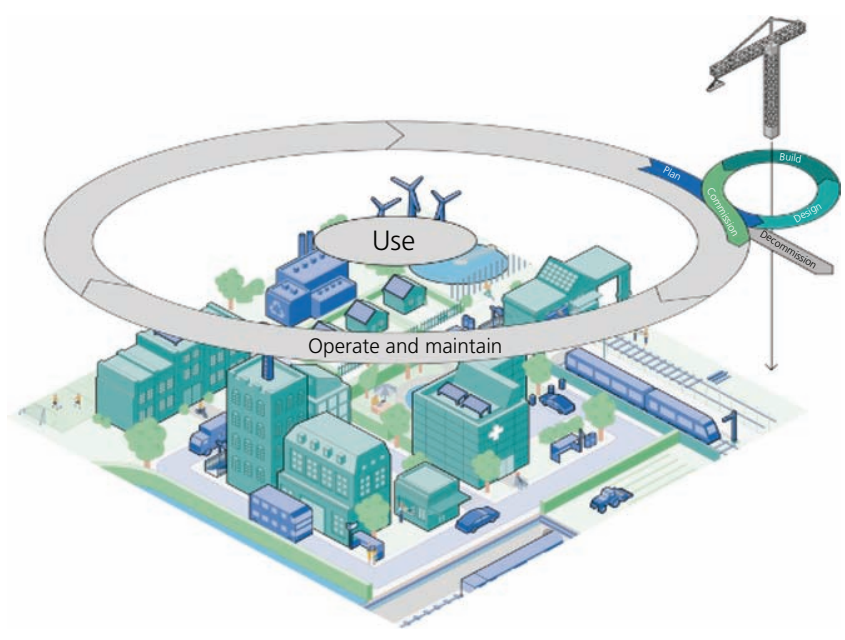

Figure 3. The use of the infrastructure system is the dominant part of the life cycle, with delivery of new projects being interventions on the system overall (Schooling et al., 2020) 
Smart Infrastructure and Construction

Volume 173 Issue 1
Flourishing systems: re-envisioning

infrastructure as a platform for human

flourishing

Schooling, Enzer and Broo
In the UK, we have been seriously building infrastructure for more than 200 years and we have also been connecting it all up. Now, assets and networks are inextricably linked across social and economic infrastructure and with the natural environment (Figure 4). Our infrastructure has become the most complex and most essential machine ever built. Interconnections and interdependencies between economic and social infrastructure and the natural environment include ecosystem services, flood alleviation, recreation, resources and waste disposal. While protecting and improving the environment is a top government priority (HM Treasury, 2020), significant strategic investment is still required to upgrade or supplement it in order to accommodate population growth and demographic shifts, address climate change, deliver increased digital and physical connectivity and achieve a higher level of resilience against various potential disasters (NIC, 2019).

While each new asset was built to a plan, the system of systems that has emerged has neither an overall design nor a strategy for its interconnections, resilience or long-term outcomes. This needs to be addressed because silos in policy, investment decision making, development and operation produce suboptimal outcomes. For example, the shift towards greater use of electric vehicles will clearly need a strategy that is shared between the transport and energy sectors - who funds the charging infrastructure, and beyond consuming power, what contribution should vehicles make to the grid? A paradigm shift is required: we must recognise infrastructure as a system of systems and manage it accordingly. The capabilities and tools to enable such a paradigm shift are already becoming available, such as systems engineering, complexity science and federated digital twins. We now need a systems-based strategy for national infrastructure.

National infrastructure strategies must address the whole system, the existing as well as new infrastructure. To obtain more from what we already have, as well as from what we will build, we must address the connections and interdependencies between sectors. This includes transforming current infrastructure assets to smart infrastructure assets by, for instance, enabling smart sensing, monitoring and analysing capabilities through data (Broo and Schooling, 2020).

We need effective metrics for infrastructure performance. These must address

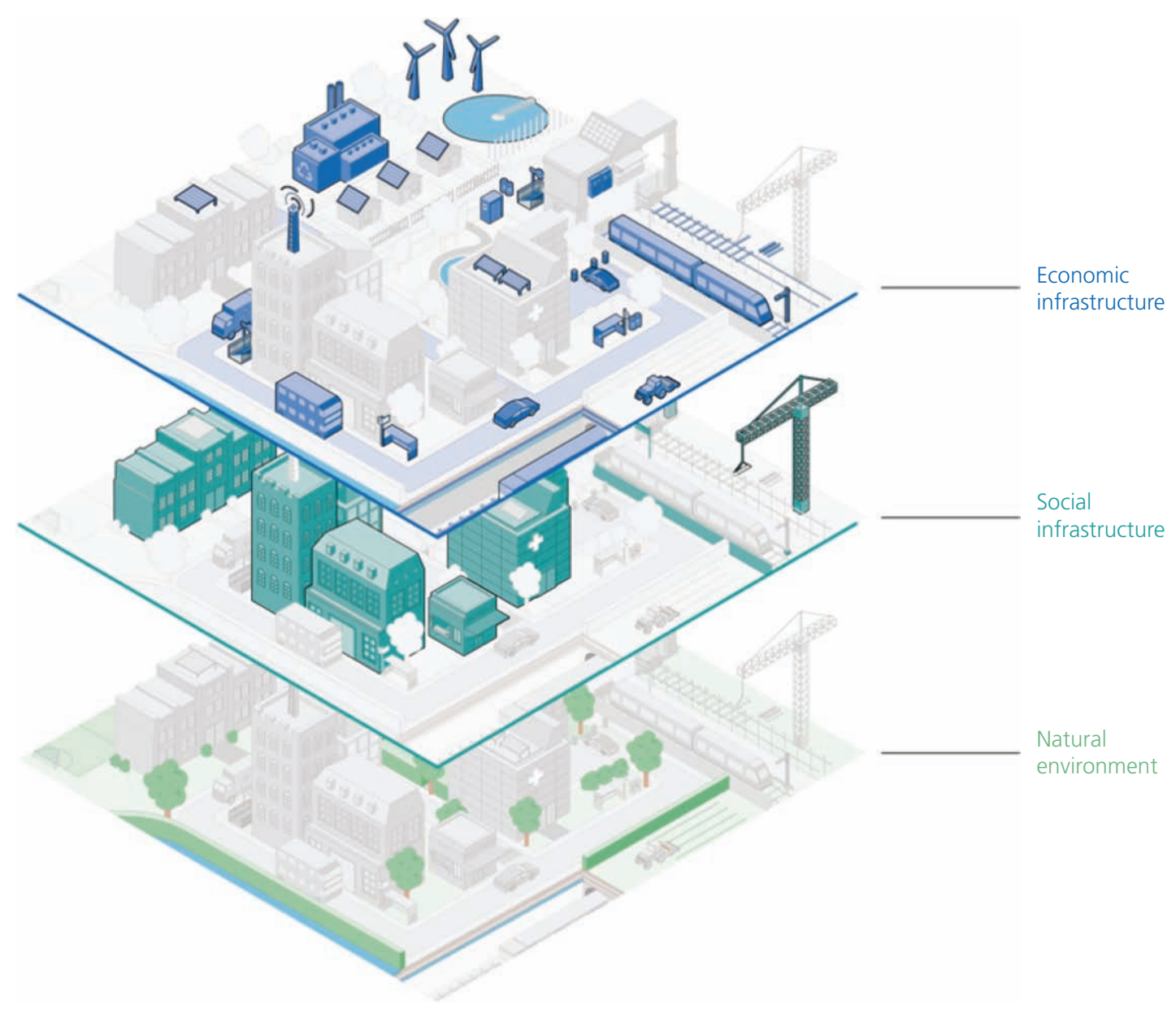

Figure 4. Interconnection between economic, social and natural infrastructure (Schooling et al., 2020) 
Smart Infrastructure and Construction

Volume 173 Issue 1
Flourishing systems: re-envisioning

infrastructure as a platform for human

flourishing

Schooling, Enzer and Broo
- system performance - how effective and efficient the system is

- service performance - how it feels for the end users.

For instance, Oswald et al. (2011) suggested developing national infrastructure index by considering a four-step process. Firstly, understand, conceptually, the entire system. Secondly, identify representative indicators. Thirdly, quantify the degree to which the needs of business are met. Lastly, conduct a participative process. Such metrics would allow the status quo to be understood, improvement targets to be set and progress to be measured.

Some important existing measures, such as construction productivity, are concerned only with asset creation, while major national metrics, such as gross domestic product growth and productivity, do not capture the elements of development, such as progress towards achieving net-zero greenhouse gas (GHG) emissions or increasing the resilience of the infrastructure system as a whole. A focus on the contribution of infrastructure to human flourishing would invite closer examination of whether its ultimate objectives for society are being met. To do so, we need to understand infrastructure better if we are to manage it better. The questions in Table 1, derived from 'enduring questions' of Australia's infrastructure needs (DIRDC, 2017), indicate what we need to know about our system of systems.

\subsection{Sustainability}

Sustainability decisions ensure that society's evolving needs can be met by the built and natural environments in perpetuity. Infrastructure systems should be sustainable, secure and resilient

Table 1. Enduring questions of Australia's infrastructure needs

\begin{tabular}{|c|c|c|}
\hline $\begin{array}{l}\text { Infrastructure } \\
\text { baseline }\end{array}$ & a & $\begin{array}{l}\text { What infrastructure do we have? } \\
\text { What is its capacity, geospatial location } \\
\text { and value? } \\
\text { What is the condition of the } \\
\text { infrastructure? } \\
\text { What services does it provide? }\end{array}$ \\
\hline \multirow[t]{3}{*}{$\begin{array}{l}\text { Infrastructure } \\
\text { performance }\end{array}$} & घ & $\begin{array}{l}\text { How well does the infrastructure perform } \\
\text { as a system? }\end{array}$ \\
\hline & घ & $\begin{array}{l}\text { How well does the infrastructure perform } \\
\text { as a service for end users? }\end{array}$ \\
\hline & a & $\begin{array}{l}\text { What is the connection between } \\
\text { infrastructure performance and key } \\
\text { national metrics? }\end{array}$ \\
\hline \multirow[t]{3}{*}{$\begin{array}{l}\text { Infrastructure } \\
\text { impacts }\end{array}$} & घ & $\begin{array}{l}\text { What are the environmental impacts of } \\
\text { infrastructure? }\end{array}$ \\
\hline & घ & $\begin{array}{l}\text { What are the social impacts of } \\
\text { infrastructure? }\end{array}$ \\
\hline & घ & $\begin{array}{l}\text { What are the economic impacts of } \\
\text { infrastructure? }\end{array}$ \\
\hline \multirow[t]{2}{*}{ Infrastructure use } & घ & How do people use infrastructure? \\
\hline & a & How do businesses use infrastructure? \\
\hline \multirow{4}{*}{$\begin{array}{l}\text { Infrastructure } \\
\text { systems data }\end{array}$} & घ & What infrastructure systems data exist? \\
\hline & घ & $\begin{array}{l}\text { What is the quality and consistency of } \\
\text { infrastructure data? }\end{array}$ \\
\hline & a & $\begin{array}{l}\text { What additional data would enhance } \\
\text { decision making? }\end{array}$ \\
\hline & घ & $\begin{array}{l}\text { Which better decisions would improve } \\
\text { outcomes? }\end{array}$ \\
\hline
\end{tabular}

in order to promote the long-term viability of the society it supports. Infrastructure is an amazing interconnected machine that underpins and serves society. For as long as we want society to function, we must keep that machine working - and develop it to meet evolving needs. This will become increasingly difficult unless we address the challenges of material resource constraints, pollution, the impacts of climate change and the transition of the whole economy to net-zero GHG emissions.

Today's infrastructure has been sustained over time through maintenance, repair and adaptation. However, 'sustained' is not the same as 'sustainable'. Our system of systems is resource hungry and wasteful; vulnerable to environmental, social and economic pressures; and at risk from accidental or malicious security breaches.

Infrastructure must work within its fair share of the planet's means. Energy and materials inputs and waste outputs must be within the environment's capacity. At a high level, this is simple, but in practice, it will require concerted effort by the industry over the years to come. We urgently need to shift the dialogue towards making the system sustainable, thinking about cross-system effects and addressing future as well as present challenges. For example, the shift towards electric cars must reduce whole-system impacts, not just emissions; the impact of lithium mining and managing spent batteries must be part of the equation.

Where infrastructure systems have failed, it has not taken very long for effects to cascade, knocking out critical services and, in some instances, challenging social order. Examples include the flooding of Lancaster, UK, during Storm Desmond in 2015 (Kemp, 2016); the impact of Hurricane Katrina on New Orleans, USA, in 2005; and the failure of municipal waste management in Athens, Greece, in 2010 (Renn et al., 2011). In its Global Risks Report 2019 (and consistently for the last decade), the World Economic Forum (WEF, 2019) places the failure of critical infrastructure among the top ten risks to the global economy, ranked by likelihood and severity of impact.

There has been modest progress in reducing infrastructure carbon emissions. Parts of the industry have recognised that reducing carbon dioxide can reduce cost (HM Treasury, 2013) - leading practitioners are achieving in excess of $60 \%$ carbon dioxide savings in capital investment programmes and $30 \%$ in operation. Yet, beyond a handful of pioneering companies, even engagement for reducing carbon emissions is low. To address the sustainability challenges, we have even to go further on resource efficiency and moving towards a circular economy.

Digital technology can help here, enabling us to

- manage assets through their life cycles

- manage material resources through many life cycles - a key enabler of the circular economy in infrastructure

- understand and manage complex trade-offs that are required between sectors - for example, to achieve net-zero GHG emissions. 
Smart Infrastructure and Construction

Volume 173 Issue 1
Flourishing systems: re-envisioning

infrastructure as a platform for human

flourishing

Schooling, Enzer and Broo
For as long as we want society to function, we must keep infrastructure working. It will become increasingly difficult to sustain infrastructure and society unless the system itself becomes sustainable, secure and resilient.

In 2015, the UN set out 17 global Sustainable Development Goals (SDGs) (UN, 2015) with 169 sub-targets, almost three-quarters of which are directly or indirectly influenced by the provision of infrastructure (Figure 5). Infrastructure can contribute significantly towards achieving the SDGs. However, infrastructure itself must be sustainable. This requires us to consider how each asset-level intervention affects the system.

Recognising that infrastructure is systems based and interconnected reveals that 'soft infrastructure' is also necessary - frameworks and organisational structures to understand, plan, coordinate, manage and obtain more out of the systems and make them sustainable. Soft infrastructure helps protect hard infrastructure from failing and protect people from the consequences of failure.

Extrapolating from data on the construction industry (Rhodes, 2015), it is estimated that around $15 \%$ of the UK's workforce are employed in the built environment sector. For infrastructure to be sustainable, the people who sustain the system of systems must themselves be supported in their well-being and safety, their employment security and in the development of their capability.

\subsection{Digitalisation}

We must ensure that, in harnessing the power of information and data, we deliver better decisions that lead to better outcomes for people and society. Infrastructure as a cyber-physical system should realise the benefits of digital transformation across the built environment. Improved decision making requires that digital assets be properly valued and managed. Without a systems view of infrastructure, we will not be able to access the full value of digital transformation.

With the ongoing digital transformation of the infrastructure industry, we have the opportunity to deliver huge benefits for people - for whom infrastructure ultimately exists. Part of this is economic benefits, estimated at $£ 7$ billion/year for the UK (Deloitte, 2017), which are related to improved efficiencies, increased competition and innovation and network planning and resilience. These benefits - for instance, lower costs and emissions - improve capacity management

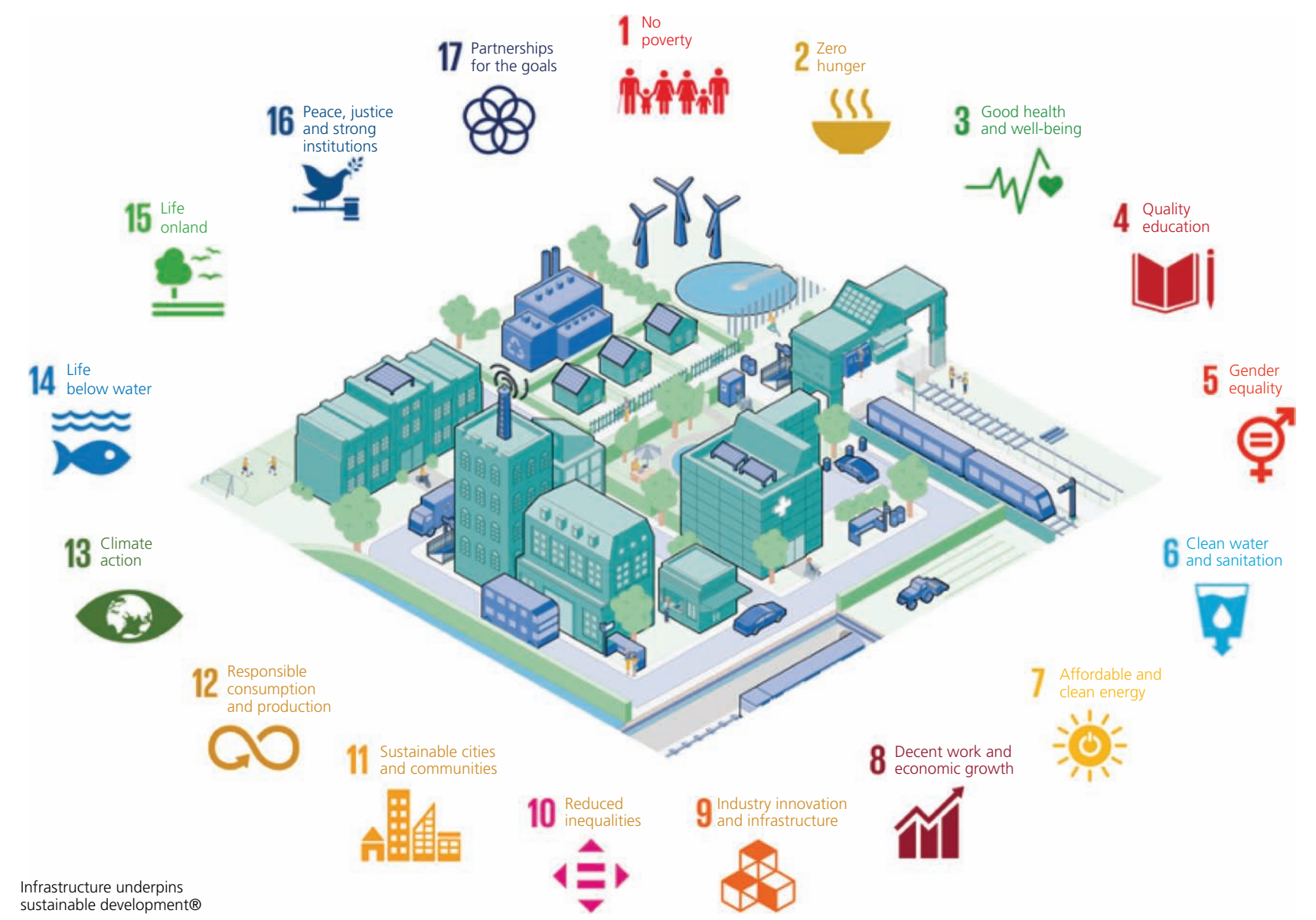

Figure 5. UN SDGs and the role of infrastructure (Schooling et al., 2020) 
Smart Infrastructure and Construction

Volume 173 Issue 1
Flourishing systems: re-envisioning

infrastructure as a platform for human

flourishing

Schooling, Enzer and Broo and increase outputs, which also helps improve customer savings, provide better innovative services and develop more accurate resilience models (Deloitte, 2017).

Digital transformation encompasses how we

- function as organisations

- deliver new assets

- operate, maintain and use existing assets.

Bringing digital and physical assets together creates cyberphysical systems - smart infrastructure. Effectively, this is applying the fourth industrial revolution to infrastructure (Neely et al., 2019). As we have discussed earlier in this paper, making better use of asset and systems data is central to this vision because better analysis of better data enables better decisions, producing better outcomes.

As part of this, we must recognise digital assets, such as data, information, algorithms and digital twins, as genuine 'assets', which have value and must be managed effectively and securely. In time, as data and digital assets become valued, data themselves will be seen as infrastructure because data are an engine of efficiency and growth (ODI, 2016). Therefore, we need to strengthen our data infrastructure (ODI, 2016).

Through better collection, curation and connection of data, we will create new digital assets of value for owners, operators and end users - society and nations. Accurate and accessible records of our infrastructure and built environment will aid present and future decision makers. We must recognise digital assets, such as data, information, algorithms and digital twins, as genuine assets, which have value and must be managed effectively.

Managing complex interconnected systems requires appropriate tools. Digital twins have been used successfully in the manufacturing and aerospace industries for this purpose, and they promise to release similar value in infrastructure (IET, 2019).

Through secure data sharing, digital twins can be federated to help us monitor, understand and make more informed decisions across infrastructure networks and sectors. 'National digital twins', envisaged as ecosystems of connected digital twins, have the potential not just to mirror but also to help manage and obtain more from the system of systems that is national infrastructure (NIC, 2017).

We are at a point where the vision for effective digitalisation of the whole of the built environment is no longer an impossible dream. In the UK

- The increased adoption of building information modelling enabled by the UK BIM Framework (UK BIM Alliance et al., 2020) lays an excellent foundation in information management for the industry.
- Soon, technologies such as the Internet of things, artificial intelligence and augmented and virtual reality could be integrated within digital twins to support decision making.

- An information-management framework (Enzer et al., 2019)

is being developed - an industry standard for creating interoperable systems data, which will make secure, resilient data sharing between organisations and across sectors achievable. The framework is key to unleashing the information economy and achieving federated digital twins and ultimately the National Digital Twin (CDBB, 2019).

National data strategies must address infrastructure data - how to ensure that data from assets and systems in the built environment are used to create value for the public good. Such strategies should encourage secure, resilient data sharing across organisational and sector boundaries, including within the government. In tandem, national infrastructure strategies must address digital as well as physical assets.

As our built environment and the wider economy become more information based, associated soft infrastructure will be required to keep pace. In particular, new frameworks, organisational structures and business models will be required to understand, plan, manage and regulate cyber-physical infrastructure and the related data infrastructure (Figure 6).

National digital twins - ecosystems of connected digital twins have the potential not just to mirror but also to help manage and obtain more from the system of systems that is national infrastructure.

\section{Future directions}

This section presents future directions for the industry as next steps that would enable the infrastructure to become a platform for human flourishing. For this purpose, we suggest five steps to follow.

Firstly, the industry should focus on a vision where we recognise infrastructure as a system of systems that provides a platform for human flourishing, re-envision the infrastructure industry accordingly and establish a people-focused, systems-based view of infrastructure.

Secondly, the national infrastructure strategy should focus on providing a systems-based view of infrastructure that addresses both existing and proposed infrastructure. Additionally, this strategy should provide a road map to advance digitalisation and address digital as well as physical assets.

Thirdly, the national data strategy (DCMS, 2020) must address infrastructure data so that data from assets and systems in the built environment are used to create value for the public good. Furthermore, the national data strategy should provide strategies that support secure, resilient data sharing across organisational and sector boundaries, within and beyond infrastructure. 


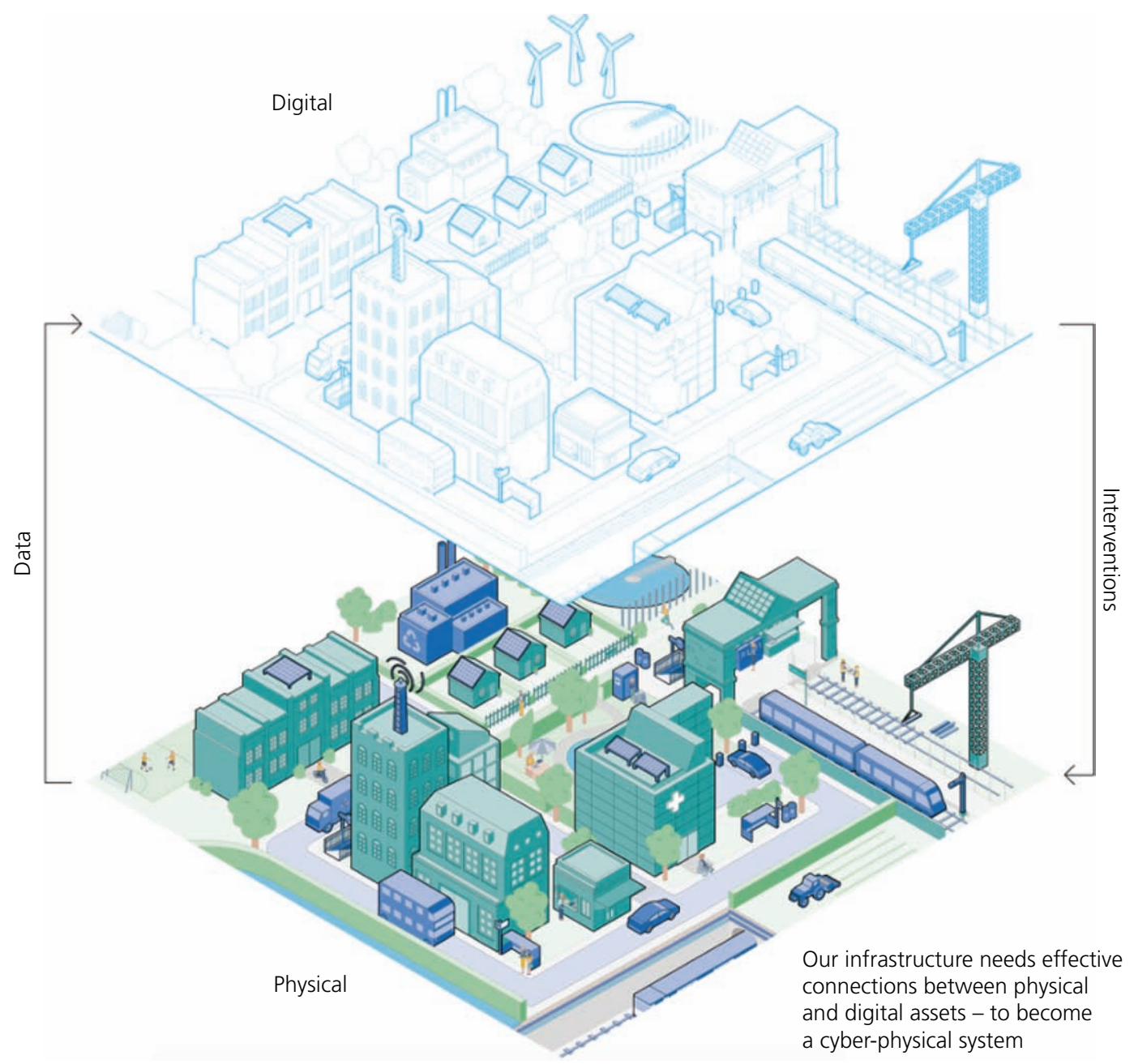

Figure 6. Effective connections between physical and digital assets are necessary to enable cyber-physical infrastructure systems (Schooling et al., 2020)

Fourthly, the industry should develop and define reliable performance and resilience metrics for infrastructure to address its performance and resilience as a system and as a service. In addition to these metrics, it is necessary to develop understanding of the relationship between infrastructure performance and key social, environmental and economic metrics.

Lastly, it is vital to enable sustainable decision making. For that purpose, we suggest developing systems-based tools, such as connected digital twins, to inform and enable strategies for addressing systemic challenges, and addressing resource use and efficiency, making a deliberate move towards the circular economy in infrastructure.

\section{Conclusions}

This paper aims to provide a way to re-envision infrastructure as a platform for human flourishing. Through this approach, the infrastructure industry can improve its ability to deliver not only desirable outcomes for people and the wider environment but also to integrate new assets properly into the existing system. Moreover, this re-envisioning of the role of infrastructure would release available value from what we have already built, provide the resilience that society requires of its infrastructure and unlock the potential of digital transformation across the built environment.

\section{Acknowledgements}

This paper has received support from the Centre for Digital Built Britain at the University of Cambridge, which is within the Construction Innovation Hub and is funded by UK Research and Innovation through the Industrial Strategy Fund. The authors would like to acknowledge the support of the Innovate UK-funded Construction Innovation Hub, the Engineering and Physical Sciences Research Council/Innovate UK-funded Cambridge Centre for Smart Infrastructure and Construction (Grant Numbers EP/ N021614/1 and 920035) and the Centre for Systems Engineering and Innovation at Imperial College London, which collectively funded the research that contributed to this paper. 


\section{REFERENCES}

Batty M (2018) Digital twins. Environment and Planning B: Urban Analytics and City Science 45(5): 817-820, https://doi.org/10.1177/ 2399808318796416.

Bolton A, Butler L, Dabson I et al. (2018) The Gemini Principles. Centre for Digital Built Britain, Cambridge, UK. See https://doi.org/10.17863/ CAM.32260 (accessed 19/02/2021).

Bowers K, Buscher V, Dentten R et al. (2018) Smart Infrastructure: Getting More from Strategic Assets. Cambridge Centre for Smart Infrastructure and Construction, Cambridge, UK. See https://wwwsmartinfrastructure.eng.cam.ac.uk/files/the-smart-infrastructure-paper (accessed 19/02/2021).

Broo DG and Schooling J (2020) Towards data-centric decision making for smart infrastructure: data and its challenges. IFAC-PapersOnLine 53(3): 90-94, https://doi.org/10.1016/j.ifacol.2020.11.014.

CDBB (Centre for Digital Built Britain) (2019) National Digital Twin Programme. CDBB, Cambridge, UK. See https:/www.cdbb.cam.ac.uk/ what-we-do/national-digital-twin-programme (accessed 19/02/2021).

$\mathrm{ClH}$ (Construction Innovation Hub) (2020) An Introduction to the Value Toolkit. CIH, UK.

CSIC (Centre for Smart Infrastructure and Construction) (2019) Smart Sustainability: Exploiting Data in Engineering to Mitigate Climate Change. CSIC, Cambridge, UK. See https://www-smartinfrastructure. eng.cam.ac.uk/files/smartsustainability (accessed 19/02/2021).

DCMS (Department for Digital Culture Media and Sport) (2020) National Data Strategy. DCMS, London, UK. See https://www.gov.uk/ guidance/national-data-strategy (accessed 19/02/2021).

Deloitte (2017) New Technologies Case Study: Data Sharing in Infrastructure. Deloitte, London, UK

DIRDC (Department of Infrastructure Regional Development and Cities) (2017) National Infrastructure Data Collection and Dissemination Plan. DIRDC, Canberra, Australia.

Enisa (EU Agency for Cybersecurity) (2019) Smart Infrastructure. Enisa, Athens, Greece. See https://www.enisa.europa.eu/topics/iot-and-smartinfrastructures/smart-infrastructure (accessed 19/02/2021).

Enzer M, Bolton A, Boulton C et al. (2019) Roadmap for Delivering the Information Management Framework for the Built Environment. CDBB, Cambridge, UK. See https://doi.org/10.17863/CAM.38227 (accessed 19/02/2021).

Fiksel J (2003) Designing resilient, sustainable systems. Environmental Science and Technology 37(23): 5330-5339, https://doi.org/10.1021/ es0344819.

Hall JW, Tran M, Hickford AJ and Nicholls RJ (eds) (2016) The Future of National Infrastructure: A System-of-systems Approach. Cambridge University Press, Cambridge, UK.

HM Treasury (Her Majesty's Treasury) (2013) Infrastructure Carbon Review. HM Treasury, London, UK. See https://www.gov.uk/ government/uploads/system/uploads/attachment_data/file/260710/ infrastructure carbon review 251113.pdf.

HM Treasury (2020) National Infrastructure Strategy. HM Treasury, London, UK.

ICE (Institution of Civil Engineers) (2020) See https://www.p13.org.uk (accessed 19/02/2021).

IET (Institute of Engineering and Technology) (2019) Digital Twins for the Built Environment. IET, Stevenage, UK. See https://www.theiet. org/impact-society/sectors/built-environment/built-environment-news/ digital-twins-for-the-built-environment (accessed 12/11/2019).

Kamargianni M, Li W, Matyas M and Schäfer A (2016) A critical review of new mobility services for urban transport. Transportation Research Procedia 14(0): 3294-3303, https://doi.org/10.1016/j.trpro.2016.05. 277.

Kashdan TB, Biswas-Diener R and King LA (2008) Reconsidering happiness: the costs of distinguishing between hedonics and eudaimonia. Journal of Positive Psychology 3(4): 219-233, https://doi. org/10.1080/17439760802303044.
Kemp R (2016) Living without Electricity: One City's Experience of Coping with Loss of Power. Royal Academy of Engineering, London, UK. See https://www.raeng.org.uk/publications/reports/living-withoutelectricity (accessed 19/02/2021).

Neely A, Schooling J, Boulton C and Lamb K (2019) Developing the Capabilities for a Digital Built Britain: A Summary of 'Capability Framework and Research Agenda for a Digital Built Britain'. CDBB, Cambridge, UK. See https://www.cdbb.cam.ac.uk/news/capabilityframework-and-research-agenda-digital-built-britain (accessed 19/02/2021).

NIC (National Infrastructure Commission) (2017) Data for the Public Good. NIC, London, UK.

NIC (2019) Resilience Study: Scoping Report. NIC, London, UK. See https://www.nic.org.uk/wp-content/uploads/

NIC_Resilience_Scoping_Report_September_2019-Final.pdf (accessed $19 / 0 \overline{2} / 2021)$

ODI (Open Data Institute) (2016) Data Infrastructure. ODI, London, UK. See https://theodi.org/topic/data-infrastructure/ (accessed 19/02/2021).

Oswald M, Li Q, McNeil S and Trimbath S (2011) Measuring infrastructure performance: development of a national infrastructure index. Public Works Management and Policy 16(4): 373-394, https://doi.org/10. 1177/1087724X11410071.

Renn O, Jovanovic A and Schröter R (2011) Social Unrest. Organisation for Economic Co-operation and Development, Paris, France.

Rhodes C (2015) Construction Industry: Statistics and Policy. House of Commons Library, London, UK, Briefing Paper No. 01432.

Schooling J, Burgess G and Enzer M (2020) Flourishing Systems: Reenvisioning Infrastructure as a Platform for Human Flourishing. CDBB and CSIC, Cambridge, UK. See https://doi.org/10.17863/CAM. 52270 (accessed 19/02/2021).

Smith TW (1999) Aristotle on the conditions for and limits of the common good. American Political Science Review 93(3): 625-636, https://doi.org/10.2307/2585578.

UK BIM Alliance, BSI and Centre for CDBB (2020) UK BIM Framework: The Overarching Approach to Implementing BIM in the UK. UK BIM Alliance, London, UK. See https://ukbimframework.org (accessed 19/02/2021).

UN (2015) Transforming Our World: The 2030 Agenda for Sustainable Development. UN General Assembly, New York, NY, USA.

WEF (World Economic Forum) (2019) Global Risks Report 2019. WEF, Geneva Switzerland.

\section{How can you contribute?}

To discuss this paper, please email up to 500 words to the editor at journals@ice.org.uk. Your contribution will be forwarded to the author(s) for a reply and, if considered appropriate by the editorial board, it will be published as discussion in a future issue of the journal.

Proceedings journals rely entirely on contributions from the civil engineering profession (and allied disciplines). Information about how to submit your paper online is available at www.icevirtuallibrary.com/page/authors, where you will also find detailed author guidelines. 